\title{
The Political Unconscious of Practice Theory: Populism and Democracy
}

\author{
Michael Strand \\ Department of Sociology \\ Brandeis University \\ mstrand@brandeis.edu
}

\begin{abstract}
This article attempts a self-clarification of practice theory by providing a genetic history of "practice" as a figure in social thought. This locates two different versions of practice theory in Marx's "practical question" and Hobbes' "Kingdom of Darkness," respectively, and shows how both historically comprise a practical critique of testing reason. This article examines how the practical critique performs a dialectic of politicization and depoliticization that finds family resemblances and paradoxical alignments between the political left and right. The article evaluates the strength of the practical critique and asks whether it results in a power politics with both left and right versions.
\end{abstract}




\section{Introduction}

When Sherry Ortner first codified the practice trend in the human sciences, she recognized that the "most significant forms of practice are those with intentional or unintentional political implications ... The study of practice is after all the study of human action, but from a particular-- -political---angle" (1984: 149). For Ortner, this means that certain practices have the consequence of producing and reproducing some set of structural effects. Practices are political because they have structural consequences that are unequal, exclusionary and discriminating, but unintendedly so relative to the value-attachments or beliefs that social agents purport to have (Bourdieu 1979: 131).

In the more than 30 years since Ortner wrote her paradigmatic article, practice theory has become one of the most prevalent theoretical frameworks in the human sciences. However, as Stephen Turner (2002) argues, its enormous influence has come at a price, one that adds an important and surprising twist to the connection between practice theory and politicization. "What now appears to us as practice theory," Turner writes (2002: 22), has hidden a very different past for the concept, one that lends practice an antithetical purpose. Instead being political as a subtle mechanism that reproduces social inequality, practice is, by its nature, nonideological, which makes it politically appealing for an entirely different set of reasons.

Turner concentrates here on mid-20th century English conservativism and the efforts of theorists to recuperate the idea of "tradition" as a counterweight to the kind of hyperpoliticization that had eroded liberal-democratic institutions on the continent in the preceding decades. From this perspective, as more and more domains of social life are made ideological, this erases the barriers that kept them non-political. As politicization advances, the tendency is to make politics devolve into a kind of Schmittian struggle in which everything obtains an ideological significance. In this scenario, practice theories acquired appeal for the 
very fact they could not be appropriated by ideology (see Oakeshott 1962[1947]: 35-36; Shils 1958: 473).

On the one hand, then, practice theory has a politicizing effect because it brings attention to the unnoticed role of seemingly neutral or objective actions in reproducing structures of inequality and exclusion. On the other hand, practice is situated beyond the good and evil of ideologicallydriven politics and this immunity is depoliticizing by drawing attention to the limits of what can be changed. Now it might be claimed here, fairly, that what is meant by "practice" (or its cognates) in these arguments is not shared and so what is really at stake are simply differences in interpretation. In fact, the contrary is true (see Bourdieu 2000: 82-3). Both versions of practice are closely similar and they both describe practice in a way that share nearly all of the attributes that Karl Mannheim famously associated with "conservative thought" (1993[1927]). Both sides agree that practice is, by definition, "thinking concretely" and avoiding speculation (Mannheim 1993[1927]: 288). In both iterations, practice theories emphasize "the immediate, the actual, the concrete" (288). The domain of practice concerns the "pretheoretical" and the "inarticulate," with special attention to "embodying" (290). Practice also describes a strong association with history as what is "handed down," "inherited" and "inalienable" (292-93). For both varieties of practice theory, the human sciences must attend to "the actual as the producer of real factors" not to norms (295).

For Mannheim, the conservative "style of thought" was born in a post-French revolutionary Europe and marked a deliberate attempt to maintain a threatened form of life by "raising it to the level of conscious reflection ... Conservative thought saves itself ... by raising to the level of reflection and conscious manipulation those forms of experience which can no longer be had in an authentic way" (Mannheim 1993[1927]: 301). This affirms the body, the inarticulate and the concrete as traits and qualities that possess a higher degree of reality and value than what is abstract, rational, and consciously intended. Initially, this appealed to the counterrevolutionary 
impulse of conservative thought. But as Ortner describes, practice theory, or "thinking concretely," concentrating on "the immediate, the actual, the concrete," the "pretheoretical" and the "inarticulate," as the "producer of real factors" instead of beliefs or norms, later comes to serve the very different purpose of "[penetrating] into the workings of asymmetrical social relations ... of domination" (Ortner 1984: 157). Seeking out and raising to consciousness these non-normative practices, located outside of highly intentional moments of action, which maintain structural inequality, has a destabilizing and even revolutionary impact. Something puzzling is at stake, then, if different varieties of practice theory are taken into account and its common theoretical core (body, history, concrete) appears to enable politicization with revolutionary consequences and also depoliticization with counterrevolutionary consequences.

The argument below is that practice theories have a connection with politicization because they reveal the antithesis of explicit rules and principles and of official representations that characterize truth or worth through tests. What makes practice theory politicizing or depoliticizing is that politicizing versions use the unmasking of practice to allow for critical reflexivity and autonomy in relation to practical logics. Depoliticizing versions emphasize the practical as a separate domain that cannot be recouped for those purposes because it can only be continuously confirmed. Politicizing and depoliticizing mean something for practice theory because of the genealogical association between practice and tests.

Tests allow for a non-deterministic understanding of social life by foregrounding "the various degrees of uncertainty haunting situations in social life" (Boltanski and Chiapello 2005: 30). More formally, tests are events that create and then absorb uncertainty by making demonstration and agreement possible, semiotically connecting performance and competence, and speaking for the result as proof of strength, intelligence, skill, group identity, or something transcendent, like justice, nature, God's will, even love. On these terms, "modernity" signals a transformation in predominant tests: from pure strength to legitimate status. Power becomes "symbolic 
power." Rationalism, meanwhile, refers to justificatory constraints that increase the scale of tests (Potthast 2017; Boltanski 2011; Lemieux 2008).

In these circumstances practice theories appear as a critique of testing reason and practice itself becomes charged with a contradictory political mission: both to politicize tests that seem transcendent of objective relations of domination, and to depoliticize those areas of social life that would be displaced should they be put to the test. The present study recovers these associations by tracing a genealogy of both left and right practice theory. This clarifies otherwise confusing political fractures and establishes the critical appeal of practice theory as a way to emplot the experience of tests in order to challenge judgments that appear beyond dispute. But it also begs the question whether practice theory is simply power politics in either left or right versions, and whether its inverse - truth politics—with recourse to a transcendent court of appeal, is still possible.

\section{What is Practice Theory?}

\subsection{The Allegory of the Charwoman}

Consider the famous set-piece in Bourdieu's Outline of a Theory of Practice, arguably the best demonstration of the system-reproducing effects of practice: a "possessor of economic and cultural capital ... lavishes generosity, kindness and politeness on his charwoman (and other 'inferior social agents')" but by "choosing the best investment for his money, or the best school for his son ... he perpetuates the relation of domination to his charwoman and even her descendants" (1977: 189-90). Bourdieu refers to these perpetuating actions as having some relation to "objective mechanisms." While they might seem normal or even benign, they are in fact politically significant:

But social reality had another trap in store for science: the existence of mechanisms capable of reproducing the political order, independently of any deliberate intervention, makes it possible to recognize as political, amongst the different types of conduct directed 
towards gaining or keeping power, only such practices as tacitly exclude control over the reproduction mechanisms from the area of legitimate competition ... The greater the extent to which the task of reproducing the relations of domination is taken over by objective mechanisms, which serve the interests of the dominant group without any conscious effort on the latter's part, the more indirect and, in a sense, impersonal, become the strategies objectively oriented towards reproduction (1977: 189; my emphasis).

Bourdieu (2000: 104-105) argues that relative autonomy is the key to this logic of domination. The dominant can only be dominant if they "secure recognition, which is nothing other than misrecognition" (104). Privilege, inequality and hierarchy can exist against a moral background of equality but only when produced "through powers that cannot be suspected of obeying force ... [The] legitimating efficacy of an act of recognition ... varies with the degree of independence of the agent or institution that grants it" (104; emphasis mine).

Bourdieu includes all significant elements found in the political unconscious of practice theory. The political order he describes governs through powers not "suspected of obeying force" because they appear transcendent and not immanent to the world or a class. Bourdieu (1990: 130) traces a change in domination toward "objective, institutionalized mechanisms such as the 'selfregulating' market." Foucault identifies a shift from "the ancient right to take life or let live ... [to] a power to foster life or disallow it to the point of death" and the role that knowledge, expert judgment and deployment of an "ideal" or "imaginary point" like sexuality plays in this (1990[1978]: 155). Hayek assails the "mirage of social justice" and its justification of state interventionism as an "anthropomorphism or personification by which naive thinking tries to account for all self-ordering processes" (1978: 63). Oakeshott warns against the state becoming an "enterprise association" organized around "deploying [its subjects] productive energies and talents according to a 'scientifically deliberated' plan' (1975: 290-291).

There is a common critique here, as well as a common narrative, one that describes power mediated through some transcendent means (e.g. objective mechanisms, ideal or imaginary point, mirage, scientifically-deliberated plan) made stronger by this disguise, though it remains power. As Bourdieu puts it, "raw power ... acts according to mechanical efficiency ... genuine 
power acts as symbolic power ... [It] has no value or social efficacy unless conceded ... [The] symbolic efficacy of an act of legitimation increases with the ratio of recognized independence" (1996: 383). This ratio is at its highest when it passes through a quasi-Platonic space, that impartially dispenses an effect, in all appearances removing power from a brutal exchange in the terrestrial world.

My stance is that the transformation that disguises power, and which practice theorists reveal, is connected to tests, how tests use demonstrations to generate a legitimating power, and how this means they engage the political by their very nature (Boltanski 2011; Potthast 2017). "A test is a situation that makes obvious that the social order is neither eternal nor unbreakable. It's a situation where people renegotiate, at least partially, the cooperation and the hierarchy between them ... [Any] test creates a social transformation" (Lemieux 2008). Because tests must generate assent, they serve as a kind of sovereign point of exception that can reorder social relations in an instant, linking micro situations with macro and fixed outcomes. The test mechanism and the leverage it gives for those who can control the demonstrations, and speak for a transcendent source as deciding the outcome, allows practice theorists to define apparently innocuous acts as political acts, because of how they dictate the test and use its impartial or universalizing imprimatur, or place boundaries around the political by putting a tradition or institution beyond testing or justification, removing it from reasoned dispute by making it practical and incapable of being designed or evaluated on any terms.

\subsection{The Allegory of Fishing}

Bourdieu's allegory of the charwoman reveals, in nuce, the politicizing effect of a practice theory and all this presupposes. But consider a different allegory now: Oakeshott's (1962) allegory of fishing. Fishing can be an activity meant to reach a goal or purpose, and this will lead one to be critical of it: "[discarding] practices which prove unsuccessful, you will not be bound by unprofitable attachments ..." But for Oakeshott, fishing qualifies as practice precisely because it 
is engaged in "for its own sake." The enjoyment is found in "exercising a skill," which means you do not ask the why or the how of fishing, or inquire into who might benefit from it (1962: 178). Any standard that tests the quality of fishing cannot alter its immanent appeal. For Oakeshott, that appeal perfectly exhibits the "conservative disposition" and its preference for preservation against change (169).

Thus, in these two allegories, Bourdieu and Oakeshott communicate hidden meanings about the nature of practice, by revealing aspects of the political unconscious that animates it, and makes the class-based nature of certain actions political and the traditional or inherited nature of other actions unpolitical. But it is Janus-faced: there is a left and a right practice theory. The differences can be diagrammed as follows:

\section{$<<<$ Table 1 about here $>>$}

Practice theorists attend to history, the body, routine and subconscious process, favoring these over the mind, consciousness or subjective meaning. Practice theories bring to light historicallyfashioned and oversubjective background conditions (e.g. limits) that shape how humans have agency in the world and what kind of agency they have (Reckwitz 2002: 245). But only for left

practice theorists are these conditions locatable, historical and differentiated. Right practice theorists draw attention to temporality instead; something like fishing becomes no more particular than a "general activity."

\subsection{Critique of Testing Reason}

Bourdieu's allegory of the charwoman is unmistakably critical in tone. But who, or what, is he critical of? He makes clear in this example that a "legitimate competition" serves to uphold a condition of privilege. The legitimate competition in this case refers to educational admission or performance on a "self-regulating market." It is these legitimate competitions that the action of 
the "possessor of capital" leverages in this case, to uphold a privileged position across generations, regardless of how polite or friendly he otherwise is. We can understand these as instances of tests. This means, at least if we trust the allegory, that the occasion for practice theory is a critique of tests. A similar guiding thread can also be found in Foucault: for example, his (1967[1961]) attention to the practice of confinement, quarantine, examination and separation that determines an existential status as either "mad" or "reasonable." Those are practice-relative distinctions. Whatever universal or innate patina they might acquire, a permanent inscription, results from the power of these demonstrations; without them, the distinction does not generate the same stigma.

As for right practice theorists, Hayek and Oakeshott share a mutual criticism of planning or purpose-based governance and seek to limit the possibilities of rational design and control. For them, the occasion for practice theory is a confirmation against tests. Practice is that which eludes justification as "rational." Like fishing, it requires no justification at all. Beyond this, practice refers to some agentic capacity that remains fundamentally unknowable and uncontrollable given the nature of how our cognition acquires categories, habits and modes of conduct. The rationalist impulse, right practice theorists claim, holds a misleading and dangerous appeal, as planning or purpose must alter institutions or traditions that have not been designed and can never be fully understood. Any effort to make action reliant on the conscious mind, operating in accordance with principles that transcend the immediate situation, will be disruptive, in the same way that consciously redesigning fishing would be.

\section{Right Practice Theory}

\subsection{Hobbes, Burke and the Counterrevolutionary Lineage of Practice Theory}

For right practice theory, a practical resistance or confirmation against a transcendent standard that would test and generate a need for justification goes back at least to Hobbes and Leviathan (1982[1651]), in particular the book's infamous part IV: “On the Kingdom of Darkness." Hobbes' 
resistance provides a historicity to the form and content of right practice theories, recapitulated by later theorists in their resistance to the authority claimed by possession of a transcendent standard. The Hobbesian concern with body, and the leverage he believed it gave against a doctrine of "Abstract Essences ... certaine Essences separated from Bodies" (1982[1651]: 689), was undoubtedly a political argument in the context of the English Civil War.

The World ... is Corporeall, that is to say, Body; and hath the dimensions of Magnitude, namely, Length, Bredth, and Depth: also every part of Body, is likewise Body, and hath the like dimensions; and consequently every part of the Universe, is Body, and that which is not Body, is not part of the Universe; and because the Universe is All, that which is no part of it, is Nothing; and consequently, no where $(689$, sic).

For Hobbes, no transcendence at all should be acknowledged or used as source of power. While the Bible mentions spirits and souls in spades, for Hobbes this did not imply that they were incorporeal. The dualistic ideas of "separate essences" and incorporeal substance were meaningless to him (Hobbes 1982[1651]: 687-88). The authority claimed by the Church over individuals via their soul was meaningless. For Hobbes, belief was private and could never be fully known. This made belief an unreliable tool for controlling individuals because nobody can know what anyone else is really thinking.

It was a political motivation, then, that led Hobbes toward a view of human agency in which belief is ancillary to body and to action. For him, chasing the meaning of religious entities is chasing illusions; it is simply disruptive. Hobbes favors behavioral control, even control over sequences of thought by making them subsidiary to deductive logic, an order-producing power exercised on practice, as "public and visible," rather than "inquisitions" that attempt to dictate private belief while keeping it private.

What significance should we attach to Hobbes and these arguments? The purpose here is to illustrate how a theory of human agency empowers a political entity to forcibly prevent the threat of internecine conflict caused by "claims of knowledge" (Shapin and Schaffer 1986: 104). 
In Hobbes' view, transcendent entities (like God) were the problem because they could be allied with.

Here he finds a kindred argument in Edmund Burke, his diatribe against the French Revolution, and more specifically his vitriol for "professors of metaphysics" that supplied the kind of rationalized constructs that for him had justified revolution (Yack 1986). His response was to make a strong turn toward the body and to something resembling practice theory (see Eagleton 1982). In his critique of professors Burke in fact makes a populist turn, associating the absence of "theory" with a positive valuation of common wisdom:

It is vain to talk to them of the practice of their ancestors, the fundamental laws of their country, the fixed form of a constitution, whose merits are confirmed by the long test of solid experience ... They despise experience as the wisdom of unlettered men .. They have the 'rights of men.' Against these there can be no prescription; against these no argument is binding; these admit no temperament, and no compromise; anything withheld from their full demand is so much of fraud and injustice (1951[1790]: 59)

Burke privileges what is practical over what is transcendent and theoretical: "What is the use of discussing a man's abstract right to food or medicine? The question is upon the method of procuring and administering them. In that deliberation, I shall always advise to call upon the farmer and the physician, rather than the professor of metaphysics" (1951[1790]: 58). This uses experience not merely in distinction from rationality or expert knowledge, but as a means of counterbalancing them. In a vivid passage, Burke warns against principles, ideas, the political preoccupation with transcendent things of all sorts:

Wickedness is a little more inventive. Whilst you are discussing fashion, the fashion is gone by. The very same vice assumes a new body ... It walks abroad; it continues its ravages; whilst you are gibbeting the carcass, or demolishing the tomb. You are terrifying yourself with ghosts and apparitions, whilst your house is the haunt of robbers. It is thus with all those, who, attending only to the shell and husk of history, think they are waging war with intolerance, pride and cruelty, whilst, under color of abhorring the ill principles of antiquated parties, they are authorizing and feeding the same odious vices in different factions, and perhaps in worse(1951[1790]: 210). 
To invoke practice carries no political innocence in this view because to invoke its opposite is to mobilize an entire political program that believes agency driven by principle can lead to social harmony. Burke argues otherwise, proving the mettle of practice that always eludes any grand design, no matter how logical.

\subsection{Hayek and Oakeshott on Practice}

A counterrevolutionary Leviathan (for Hobbes) and a counterrevolutionary populism (for Burke) are linked, in this sense, to attention cast on the body, history and practical limits. In later right practice theory, a quasi-tautological emphasis on institutions and traditions recapitulates a similar move. Institutions and traditions are practical, complex and cannot be fully comprehended; yet they are celebrated and confirmed for the important role they play in the maintenance of reality as it is. No planned design is feasible, and this leads both Hayek and Oakeshott to cast surprising attention on to the body.

Hayek, for example, demonstrates this tendency in his discussion of the "price system."

The price system is just one of those formations which man has learned to use (though he is still very far from having learned to make the best use of it) after he had stumbled upon it without understanding it. Through it not only a division of labor but also a coordinated utilization of resources based on an equally divided knowledge has become possible ... [Man] has been able to develop that division of labor on which our civilization is based because he happened to stumble upon a method which made it possible. Had he not done so, he might still have developed some other, although different, civilization, something like the 'state' of the termite ants, or some other altogether unimaginable type (1948: 88-89; my emphasis).

For Hayek, the phenomenon of spontaneous order or catallaxy arises from this pursuit of individual gain. Coordination can only be indirect and unintended, regardless of best laid plans, because of cognitive limits. Hayek published The Sensory Order in 1952 in which Hebbian learning models appear to him to demonstrate that any higher-level cognitive functioning is endogenous to the neural accumulation of sensory information, which means that no "apparatus of classification [possesses] a structure of a higher degree of complexity than is 
possessed by the objects which it classifies" (1952: 185). No cognitive design can be sure of its effects because it cannot have any more knowledge than what its objects give to it.

Against postwar Keynesianism, Hayek's arguments served to limit conscious design against unplannable sources of stability: "the problem is precisely how to extend the span of our utilization of resources beyond the span of the control on any one mind; and, therefore, how to dispense with the need for conscious control" (Hayek 1948: 88). Hayek defends the price system as a system of practice that should not be politically disputed because it cannot serve any master. In perhaps the boldest demonstration of market as a non-political ordering mechanism, Hayek distinguishes between market outcomes and moral outcomes that reflect responsibility and merit:

It ought to be freely admitted that the market order does not bring about any close correspondence between subjective merit and individual needs and rewards ... Everybody, rich or poor, owes his income to the outcome of a mixed game of skill and chance, the aggregate result and the shares in which are as high as they are only because we have agreed to play that game ... And once we have agreed to play the game and profited from its results it is a moral obligation on us to abide by the results even if they turn against us (Hayek 1944: 612, 614).

Hayek uses a suspicion of planning, anchored in a sophisticated view of cognition, to celebrate the price system and to limit state action ("planning"). While Hayek and the political philosopher Michael Oakeshott were no great friends, Oakeshott demonstrates what is a similar conceptual trajectory: using a theory of agency that, as practice theory, demonstrates the limits of knowability and links this apparently micro-condition to a systematic political recommendation, one that limits the state.

Oakeshott develops a model of habit acquisition that emphasizes the significance of repeated exposures and experiences that build habits endogenously, without having to be categorized as such. The difference between thought and experience resembles not a difference in kind but in degree of familiarity gained through repeated exposure. It is in "virtue of distinguishing and remembering likenesses and unlikenesses in what is going on [that] we come to inhabit a world 
of recognizables" (Oakeshott 1975: 3). All of this unfolds automatically, through a "continuous and unconditional engagement of learning to understand which is well on its way in even the most exiguous acts of attention" (2). Importantly, intelligence does not require a "reflective consciousness [to] supervene ... upon the confusion of all that may be going on." Indeed, reflective consciousness is itself simply another "going-on" that becomes more familiar through repeated experience (2).

As Oakeshott continues, "understanding here becomes identification," which he defines independently of "causal or marginal resemblances and differences in recognizable characteristics" that would require a conceptual architecture. Identification is instead a matter of "ideal characters specified as compositions of characteristics ... if we are asked to account for our conclusions we can only point to the marks which specify an ideal character" (1975: 5). Everything, in other words, is endogenous to this process of learning. To understand human conduct "in which an agent discloses and enacts himself is to put it into a story in which it is recognized to be an occurrence contingently related to other occurrences ... This story has no overall meaning; it is occurrences understood in terms of the meanings they acquire from their evidential contingent relationships. And the teller the story has no message for those who listen ..." (1975: 105).

Oakeshott uses his argument less to celebrate practices arrived at without design than to simply defend the overlooked need for traditions, the unformulatable lack of guidelines, bureaucratic protocol and the like, because of these practical limits of conduct. Traditions of behavior always remain elusive to explicit formulation. A "tradition of behaviour is a tricky thing to get to know. Indeed, it may even appear to be essentially unintelligible. It is neither fixed nor finished; it has no changeless centre to which understanding can anchor itself; there is no sovereign purpose to be perceived or invariable direction to be detected; there is no model to be copied, no ideal to be realized, or rule to be followed" (Oakeshott 1962: 128-29). Oakeshott's emphasis is on just how much about a tradition remains opaque to our understanding even though we enact it. The only 
thing we can claim to know are "its detail ... what has to be learned is but a coherent concrete manner of living in all its concreteness"' (128-129).

The lesson here is less one of celebration than of humility: practice is a ballast of order and stability that carries an aura of mystery and recommends against any sort of tampering, especially for a condition-bound (not transcendent) intelligence like ours. For Oakeshott, the concept of practice is very deliberately situated against human agency rooted in any way in rationality independent of habit and tradition. He places emphasis instead on "pure practice," but this ambiguous notion is made understandable only through its direct political analogue, or what Oakeshott calls a politics of "civil association," the antithesis of what he calls a politics of "enterprise association." The latter is government according to standards of efficiency, bureaucracy, rationalism, or abstract principles. Civil association, by contrast, has no substantive end. It is not trying to accomplish any particular thing. This makes a civil association similar to poetry, in Oakeshott's view, and in the same opposition between poetry and science, he finds reason to favor civil association over enterprise association.

\subsection{Populism, Neoliberalism and the Unknowability of Action}

If there is an antithesis to Oakeshott's position, John Rawls offers a telling example. This also shows the tension between practice theory and at least some major versions of liberal theory, suggested further below in the case of Bourdieu. For Rawls, there is a transcendent measure for evaluating one's place in the world: "we can think of a person as happy when he is in the way of a successful execution (more or less) of a rational plan of life drawn up under (more or less) favorable conditions, and he is reasonably confident that his plan can be carried through" (1973: 409). Compare this to Oakeshott's perspective, again derived through analogy with practice:

The world sub specie amoris is unmistakably the world of practical activity; there is desire and frustration, there is moral achievement and failure, there is pleasure and pain, and death (of one kind or another) is both a possibility and is recognized as a summum malum. Nevertheless, the image in love and friendship (what is created in these manners 
of imagining) is, more than any other engagement in practical imagining, 'whatever it turns out to be' (1962: 244).

For Oakeshott, an essential unknowability is a trademark of practice, which means that social arrangements, let alone biography, can never conform to a rational design, even a happy standard like the one proposed by Rawls. Evaluation can still occur but it must remain immanent to practice itself (similar to Alasdair Macintyre). Civil association mirrors the enjoyment the conservative disposition finds in fishing as something engaged in "for its own sake" rather than for "the purpose of a catch."

Oakeshott's position on unknowability mirrors Hayek's own version. There is a "constitutional limitation of man's knowledge and interests," Hayek argues, "the fact that he cannot know more than a tiny part of the whole of society and that therefore all that can enter into his motives are the immediate effects which his actions will have" (1948: 14). For Hayek this understanding of agency finds a similar political analogue:

The necessity ... of the individual submitting to the anonymous and seemingly irrational forces of society---a submission which must include not only the acceptance of rules of behavior as valid without examining what depends in the particular instance upon their being observed but also a readiness to adjust himself to changes which may profoundly affect his fortunes and opportunities and the causes of which may be altogether unintelligible to him (1948: 24)

Such a recognition flies in the face of the tendency to "[want] all social activity to be recognizably part of a single coherent plan" (1948: 25). For Hayek this explains the difference between "government by rules" and "government by order," of which he favors the former because it acknowledges the unknowability criterion and therefore confines "the exercise of coercive power" to the enforcement of general rules and not to any specific outcome.

\section{Left Practice Theory}

\subsection{Marx and the "Practical Question"}


To find the difference with a left practice theory requires that we begin at the beginning, or at least what is often referenced as the beginning, and historicize this form and content in the same way. Marx at the time of The German Ideology and the "Theses on Feuerbach" appears to herald a transition to practice theory, and he does so in language that resembles Burke's vivid statement given above, in Marx's case warning against a politics that refuses to recognize that "all forms and products of consciousness cannot be dissolved by mental criticism, by resolution into 'selfconsciousness,' or transformation into 'apparitions,' 'specters,' 'whimsies' but only by the practical overthrow of actual social relations" (1998[1844-45]: 61). If Marx's presentation is similar, his purpose could not be more different.

In Thesis Eleven on Feuerbach, Marx makes the proposal that "whether truth can be attained by human thinking is not a question of theory but is a practical question" (1978[1844-45]: 144). This is not because practice serves as a smallest unit, bedrock, or "my spade is turned" explanatory terminus, which only replicates theoretical truth decided a priori. Rather, the practical question is a political question because this is its practical bearing and consequence. For Marx, a practice orientation serves the truth of human thinking because it politicizes and negates the tendency Marx observed in the "political revolution" that marked the opening of bourgeois society:

The political revolution which overthrew this power of the ruler, which made state affairs the affairs of the people, and the political state a matter of general concern ... necessarily shattered everything ... which expressed the separation of the people from community life ... It dissolved civil society into its basic elements, on the one hand individuals, and on the other hand the material and cultural elements which formed the life experience and civil situation of these individuals. It set free the political spirit which had ... been dissolved, fragmented and lost in the various cul-de-sac of feudal society; it reassembled these scattered fragments, liberated the political spirit from its connection with civil life and made of it the community sense, the general concern of the people, in principle independent of these particular elements of civil life. A specific activity and situation in life no longer had any but an individual significance (1978[1843]: 45).

The political emancipation of the state amounted to an emancipation from "feudalism [the] old civil society ... [which] had a directly political character; that is, the elements of civil life such as property, the family, and types of occupation had been raised, in the form of lordship, caste and 
guilds, to elements of political life." Bourgeois society, by contrast, marks a quintessential depoliticization of civil society by making "birth, social rank, education, occupation ... nonpolitical distinctions" (Marx 1978[1843]: 33; my emphasis). Marx's point is that these are political distinctions. The "accident" (e.g. unpolitical and uncriticizable) that seems to characterize social life in bourgeois society is life understood without acknowledgement of "practical activity," which makes birth, social rank, education and occupation anything but accidental within a mode of production and (class) reproduction.

The political spirit prior to political emancipation was found only in localizing regimes; afterward, it finds expression in the "general concern of the people." For Marx, this is a depoliticizing disguise. The general concern of the people hides the fact that the political spirit of the politically emancipated state remains as localized and particular as ever, governing now on behalf of those who possess capital as the dominant social class, though it does not appear that way. The general concern as "in principle independent of particular elements of civil life" serves as a transcendent mediation that conceals this relation of power.

The difference between left and right branches of practice theory involves the different way in which they reveal practice to critique the power exercised in transcendent disguise. For right practice theories, practice has a depoliticizing effect because it confirms the limits of efforts to transform reality so it aligns with a transcendent standard. For left practice theories, practice has a politicizing effect because it recapitulates Marx's move by rendering the equivalent to a "general concern" particular and historical.

\subsection{Bourdieu and "Selecting the Elect"}

When some normative standard is defined and instituted, this assigns a reality in form of truth or worth to whomsoever is judged relative to it. This contrast can make practice evident by drawing out the implicit form of patterns that develop through judgment. What becomes 
apparent in the same way is possession of practice as now one's "reality" based on this relation to a standard and its inscription. The critical move is to recognize the standard within the same practical limits, and the capabilities it prizes as limits. Instead of signifying the total, universal, infinite or inclusive, it signifies something selective, particular, finite and exclusionary.

It is from the "dominant way of being, tacitly turned into a norm" that the exclusions are maintained through testing that confirms a deficiency or deviation. Universals in this case arise from "historical discrimination either as unmarked, neutral, universal attributes (male, white, etc) or negative, stigmatized 'natures.'" What does not prove itself to fit that mold are therefore ascribed as shortcomings linked to a "mentality ... or a quasi-nature whose historical character is obliterated." The magic of a reality test that confirms these as deviations, according to Bourdieu, is that they cease to be "seen as deriving from the particularities of a collective and individual history marked by a relation of domination" (2000: 72).

It is not a surprise, then, that Bourdieu's theory of practice stems from a longer trajectory of his research into the intensified competition (e.g. "selecting the elect") that arose in tandem with the massive postwar expansion of French higher education. Bourdieu argues that the logic of reproduction that took place before the widespread introduction of competitive entrance exams finds continuity in a disguised form. His analytic focus rests on the nature of tests and the realities they institute, as carried by forms of misrecognition that come from the assignment of worth. The analytic approach here is not dissimilar from his research on symbolic capital in fields and how assignments of worth apply to field-specific practice and habitus as relative to a standard ("symbolic capital") that is historically generated.

Bourdieu finds a practical logic operating in fields. He also finds a practical logic operating in educational testing. In both cases, a "practical logic" defines capabilities for agency by finding its limits, locating standards in history and social location, and making the "power of naming" less an unconditional permanence, that inscribes one, solidifies and justifies a certain treatment 
or fate, but something that only carries this weight of transcendent force when it is an instrument of violence.

Bourdieu's (1963) earliest work in Algeria underscores a historical particularism that, in this case, is not altogether dissimilar from Burke. His argument parallels Uday Mehta's (1990) concentration on the discrepancy between "universal capacities and the conditions for their actualization" that marked English liberal theory from Locke to the nineteenth century and which Burke resisted (438). The "exclusionary effect of the distinction between anthropological capacities and the necessary conditions for their political actualization" becomes a strategy for exclusion because it serves as proof of deficiency and inferiority.

Failing to realize the conditions of possibility "for access to what is regarded as rational economic behavior" (Bourdieu 2000: 70) is a token case of this strategy for exclusion, as it is taken to prove the inferiority of a mentality that seems by comparison deliberately irrational or inferior on the grounds of race and culture. Race and culture become relevant units in relation to the arrangement of a test. The paradox is that this is carried out by a message of inclusion that serves to perfectly arrange a reality of exclusion because of how it generates proofs that justify exclusion.

The larger part of Bourdieu and Passeron's (1977) work on educational inequality is devoted to examinations and educational processes of selection.

[The] examination is not only the clearest expression of academic values and of the educational system's implicit choices: in imposing as worthy of university sanction a social definition of know-ledge and the way to show it, it provides one of the most efficacious tools for the enterprise of inculcating the dominant culture and the value of that culture ... [The] acquisition of legitimate culture and the legitimate relation to culture is regulated by the customary law which is constituted in the jurisprudence of examinations and which owes its main characteristics to the situation in which it is formulated (142) 
The connections between formal, on-the-surface rules and the tacit qualities of practice are fundamental to this analysis of examinations, and as Bourdieu and Passeron argue further, it is from the "Jacobin ideology of formal equality of opportunity" that the university gains the relative autonomy that in turn give examinations their exalted status.

Academic examinations conform to the formula of a "reality test" in this respect, because they affirm a quasi-natural order that "holds together" through the adjustment of people to it, as they should, and situations unfold correctly, with nothing and no one out of place. So much is this true that the "probabilities for candidature," as Bourdieu and Passeron put it, are far less than the "probabilities of passing [because] pupils of working-class origin are more likely to 'eliminate themselves' ... than to be eliminated from it by the explicit sanction of examination failure" (153). The "causality of the probable" or objective expectations tending to match objective chances, as Bourdieu puts its elsewhere (1990: 67), is readily evident. The "natural" order that this reproduces holds together as the effect of a test.

Bourdieu and Passeron discredit academic examinations as techniques of representation presumed to be a neutral means of absorbing uncertainty and rendering from it a justifiable social order. Even without a theory of practice at this early stage, Bourdieu sketches the kind of dynamic that would serve as the occasion for one. Denouncing the neutrality of examinations requires that this process of "selecting the elect" (Bourdieu and Passeron 1979[1964]) be no different from other practical logics, which means the academic standard used to test serves as a universalization of a particular and can be retraced historically in its genetic condition as born from the "progressive autonomization of social microcosms based on privilege" (Bourdieu 2000: 77).

The argument, similarly, is that practice becomes a point of emphasis when testing is introduced as an evidentiary technique and uses formulas of proof. As Bourdieu and Passeron (1979: 43ff) argue (following Durkheim) the "advent of the examination" is a recent 
phenomenon, requiring the appearance of the university in its relatively autonomous form, being critical to the university as the major institution involved in the "selection process," which therefore makes it the major institution furthering the rationalization of relations of domination.

\subsection{Foucault and Critical Existential Tests}

In his seminar at the time of writing Discipline and Punish, Foucault stressed a shift from class struggle to governmentality as the central dynamic of contemporary political struggle, not least because of a "[recolonization of] political identity as political interest" in years after May' 68 in France. The French state took a keener interest in the "government of the social," and this meant the proliferation of testing (Beherent 2011). The categories (e.g. sexuality, criminality, insanity) that participate in this power dynamic insist that these topics be discussed and labels dispensed by forcing individuals into certain tests and then out of them, generating inscriptions that stabilize identities and classifications around certain observable attributes and criteria (and only these) as written into law and inscribed into reality (e.g. bodies). Persons made describable by these categories can be governed through them. The circulation of power concerns the "'will to knowledge'" that is tied, here, to arrangements of testing, their demonstrative capacity and their justification of a discipline to the body, conjured through their manufacture of readily evident proofs (Foucault 1978: 19).

Foucault's attention to practice theory precedes his later genealogies, but the work that begins with Discipline and Punish develops in tandem with the proliferation of these existential tests and the exercise of this distinct sort of disciplinary power. Examinations serve as a critical instrument through which "power ... produces reality ... the individual and the knowledge that may be gained of him belong to this production" (Foucault 1977: 194). The carceral society is the thoroughly examined and tested society in which "observing hierarchy and normalizing judgment" is all pervasive (304). Examinations remain "extremely close to the disciplinary 
power" that shape them, and they extend this to whatever subjectivity to which they are applied, thus reproducing the "schema of power-knowledge proper to each discipline" (226-27).

Foucault's critical approach thus differs in the empirical focus of Bourdieu, but shares his friend's critical strategy, anchored in the way that a practice theory reveals the historical and social location of that which claims the authority of being transcendent. "Normality" and "normativity" constitutes a main fulcrum in Foucault's thought because he performs a major critique of tests through which these categories disguise power by constructing a certain narrow pathway through which one must pass in order to be recognizable and classifiable on some public terms. Practice generates a mode of being or subjectivation because the tests that create the confines of normality are practice-relative and outside of their practical implementation as a testing procedure would mean nothing and did mean nothing at one time. Practice becomes apparent through the existential narrowness evident in the form of these "governing technologies" that inscribe this kind of limit on the body. Their antithesis are "practices of freedom" (Foucault 1997) that reclaim the presence of difference by showing how inscriptions work when they are not tests, and demonstrate the uncontrollability of experience to a single form, thus revealing it to be a single form, a limit.

Foucault exhibits the implementation of existential tests in arguments like the following:

[By] an analysis of penal leniency as a technique of power, one might understand ... in what way a specific mode of subjugation was able to give birth to man as an object of knowledge for a discourse with a 'scientific' status (1977: 24).

The object, in short, is to define the regime of power-knowledge-pleasure that sustains the discourse on human sexuality in our part of the world.... [T] he essential aim will not be to determine whether these discursive productions and these effects of power lead one to formulate the truth about sex, or on the contrary falsehoods designed to conceal that truth, but rather to bring out the 'will to knowledge' that serves as both their support and their instrument (1978: 19).

In the first case, the status of "man" as a normative construct is dethroned by connecting its presence to techniques of power that develop within the evolution of penal systems. In the 
second case, the "truth about sex" that otherwise seems inalienable from subjectivity is carried by the development of specific biopolitical practices. In both instances, the will to knowledge is imposed through evidentiary practices that demonstrate what one is.

For Foucault what attains normative status as the seemingly independent measure of truth is entangled with specific histories and power-knowledge relations that force people into certain tests of existential status. Governmentality and its later iteration in his thought as biopower historically refers to an institutionalization: one must have been through certain tests and then out of them. It is this process that institutes limits to available subjectivities, what they mean and the stigma attached to them, by speaking for some transcendent source ("reason," "sexuality," "counter-nature") as having determined the result. Practice, on the other hand, signals the relativity of these inscriptions into reality. Practice theory has a levelling effect in having a politicizing effect, by finding these arrangements to be instances of particulars made universals, a similar omission of practice-relativity, and how rendering the truth about oneself as simply an inscription by one standard also signals points of resistance to an environment peopled primarily by social types that carry the governing sanction of a test.

Foucault's oeuvre concentrates on "the critical ontology of ourselves [that involves] an archaeological and genealogical study of practices." This has for its ultimate appeal "the critique of what we are ... and the same time the historical analysis of the limits that are imposed on us and an experiment with the possibility of going beyond them" (1984: 50). Markets, too, become a "site of veridication-falsification" in neoliberalism that operates in equivalent fashion to all other discourses of truth. "Whether it is the market, the confessional, the psychiatric institution, or the prison," they each enable statements to be made in truthconditions, either true or false (Foucault 2008[1979]: 35).

In all cases, power takes the distinct form, when laundered through tests, in a paradoxical phrase: "look how oppressive it is, because it is true" (Foucault 2008[1979]: 36). Truth becomes 
oppressive in "the movement of governmentalization of both society and individuals," in which forcing people through tests and then out of them sanctions the inscriptions with a transcendent force, truth made into a "discourse," subjectivities given a permanence (Foucault 1997: 44). State rationalism takes form as governmentality, and biopolitics, in large part as the transcendent categories that create homogeneous and defined populations. Foucault himself historicizes practice theory as "the critical attitude" that is the antithesis of this arrangement because it has a levelling effect, showing the practice-relativity of what appears transcendent, showing how practices of self do not need to be (and have not always been) implemented as tests. The effect that most concerns Foucault is what he calls the "genealogy of the subject ... [that] is defined and transformed ... by the formation of certain types of knowledge" (1997: 151).

\subsection{Pluralism, Difference and Radical Equality}

For both Bourdieu and Foucault, practice theory reveals what are in both cases the limits of "official designations" of worth or truth by finding their source. This has a politicizing effect, in the same manner as Marx's "practical question," because by identifying practice it removes the impression of distance, neutrality, universality or completeness and counters it with a demonstration, in this case, of how judgments of worth or truth that have enlisted one into hierarchies and classifications, and carry a transcendent sanction, are not unpolitical. It makes sense, then, that practice theorists like Foucault and Bourdieu should concentrate on testing arrangements, because practice theories become political theories when these arrangements (governmentality, “objective mechanisms"), whether directly administered by the state or not, create homogenous and measured populations. The politicizing effect, then, translates into a camera obscura of tests. Homogeneity and hierarchy, as the effect of tests, is contrasted with pluralism and difference, as a radical equality that challenges how tests use certain practical limits (e.g. habitus, capital, practices of self) as transcendent standards. That gesture is politically active now. 
Bourdieu explicitly ties the theory of practice to a critique of state rationalism as embodied by the state nobility and their "fetishism of reason and fanaticism of the universal." That habitus enshrined by the educational system generates a sociodicy distinct from those that prevailed in the past:

The myth of the 'natural gift' and the racism of intelligence are at the center of a sociodicy, experienced by all dominant groups, beyond the differences in their declared ethical and political commitments, which makes (educationally measured) 'intelligence' the supreme principle of legitimation and which, in a civilization of 'performance' where success is everything -- imputes poverty and failure not to idleness, improvidence or vice, but to stupidity (Bourdieu 2000: 80)

When the "intelligence" of a dominant group serves to define the availability of intelligence, this generates ideological support that structures a testing arrangement as exclusionary and strong. It is nearly impossible to counter, Bourdieu claims, outside of "[recognizing] the plurality of forms of 'intelligence' and combatting by every means the destiny effect daily exerted by educational verdicts based solely on the most formal forms of this polymorphous capacity" (2000: 81).

To counter this "supreme form of symbolic violence," Bourdieu recommends a politics that we can recognize now as an extension of his practice theory: "a permanent political struggle for the universalization of the means of access to the universal" (2000: 84). This democratization of universal value, away from its monopolized possession by a state nobility, requires the democratizing effect of practice, which means a plurality of intelligence. This formula finds a political analogue in Foucault, because in the face of tests that discriminate and distinguish, creating uniformities, both Foucault and Bourdieu use practice theory to translate practice as a recognition of finitude in tension with the historical emergence of tests that only give worth or existential status to certain agentic capabilities. "Apparatus" refers the forcing of persons into certain tests, permanently inscribing them, in both Foucault and Bourdieu's work (1996: 132). "Field" by contrast, is multipolar because the standard remains contested and in flux. 
For Foucault, the arrangement prior to an apparatus-like structure, conditional on controlled tests, resembles what he describes in Madness and Civilization as a situation in which "madness" existed but was not a category produced by a test and so did not support the validity of an opposite condition ("reason").

Confinement [was] an institutional creation peculiar to the 17th century ... [In] the history of unreason, it marked a decisive event ... A sensibility was born which had drawn a line and laid a cornerstone ... Here reason reigned in the pure state, in a triumph arranged for it in advance over a frenzied unreason. Madness was thus torn from that last imaginary freedom which still allowed it to flourish on the Renaissance horizon (1967[1961]: 61)

This argument is not dissimilar from Foucault's later genealogies. The History of Sexuality begins when "sexual practice had little need of secrecy ... It was a time of direct gestures, shameless discourse, and open transgressions, where anatomies were shown and intermingled at will." This was followed by the "monotonous nights of the Victorian bourgeoisie. Sexuality was carefully confined" (1990[1978]: 3). The pivot, in these cases as in medical perception or the carceral society, is a testing arrangement that establishes the existential truth of subjectivity. Tests, examinations, and standards demonstrate those who are criminal, sick, mad and sexually deviant, just as it does their normalized opposites. These are problematized states of being that have been "put into discourse" (not everything has) when individuals are forced into a test.

Bourdieu is careful to distinguish his practice concept from that which "[falls] into the exaltation of practice and the tradition ... [an] irrationalist, reactionary populism ..." (2000: 81). A democracy of worth differs from populism because the critical target is not, as Oakeshott argued, the very idea of a standard or purpose against which to make an evaluation, but instead a situation in which those standards have been subject to monopolization and impose a symbolically powerful and still violent sanction. The "practical question" politicizes actions that work to prevent an arrangement of universal access. This is one noticeably absent an "elect" and lacks the assumption that adaptation to a single universalized standard is universally possible (if one is not stupid). 
Foucault historicizes critique to the era of governmentality and how its homogeneity and uniformity differs from a prior exercise of violent sovereignty. Existential tests are still political, and Foucault recapitulates Marx's move by politicizing the kind of arrangements that do not seem political but nonetheless are political because they fix certain tests and force individuals into certain practices that permanently mark them. Foucault's controversial and apparently praiseful claims about neoliberalism finds its basis here, mapping what a countermeasure would look like:

What appears in [American neoliberalism] is not at all the ideal or the project of an exhaustively disciplinary society in which the legal network hemming in individuals is taken over and extended internally by normative mechanisms. Nor is it a society in which the mechanism of a general normalization and the exclusion of those who cannot be normalized is needed ... [We] see instead the image, idea or theme-program of a society in which there is an optimization of the system of differences, in which the field would be open to fluctuating processes, in which minority individuals and practices are tolerated ... (2008[1979]: 259-60).

This must not be mistaken as a statement allying Foucault with Hayek. Rather, he is Hayek's Janus-face. An arrangement that, in certain respects, resembles neoliberalism finds appeal because of the optimization of difference, which Foucault underscores, but this does not translate as a universalization of the market as a privileged "site of veridication-falsification."

For Foucault, then, the "optimization of difference" is the ideal. For Bourdieu, it is the pluralization of "judges" (2000: 237). But these are not values; they do not transcend situations. To come to some reckoning with practice theory, we must recognize that these statements are an immanent morality that emerges from the reaction against transcendent constructs and their tendency to depoliticize. They make it possible to notice the unique quality and concrete content of particular sources of agency, to study them in isolation. This is Marx's truth in practice because it works against the modernizing tendency to make uniform and hierarchize under the disguise of so many equivalents to a "general concern." 


\section{Conclusion}

The argument put forward here suggests that resistance (critical or confirmatory) to transcendent power forms a contentious political source that is obscured by conventional political categories. This resistance serves as a political unconscious presupposed by theories of agency that revolve around practice. The confusion that concerns the political placement of theorists like Hayek, Oakeshott, Bourdieu and Foucault is at least partially resolved here by explaining why it is their practice theory that resonates in politically ambiguous ways.

On the one hand, right practice theory achieves mass ascendance if we associate the past halfcentury of neoliberalism and a resurgence of populism with right practice theory's leveraging of practical limits to resist efforts to plan, regulate or govern capitalist economies for social justice purposes (see Streeck 2011), and to defend and celebrate the presence of rooted and unjustifiable tradition against perceived criticism and devaluation. If my argument is correct, however, there must be a Janus-face to these strategies, an other hand.

In the same manner that populism invites a rejection of the qualified and a celebration of that which has no "official" worth, Bourdieu's practice theory finds political motivation today less as the celebration of tradition than as resistance to the authority of restrictive tests of worth propelled by the hegemony of "success." In the same manner that neoliberalism promises freedom to act on subjective knowledge and not be subject to a falsely omniscient authority, Foucault's practice theory finds political motivation today less as the demand for market freedom than as resistance to any proliferation of tests that have the effect of preestablishing and straightening a "normal" life-course.

But with this Janus-face comes a question: Has the practical critique been successful? And is the diminishment of tests inversely related to the rise of power politics with left and right versions? 
If so, then "left" and "right" continue to present themselves in paradoxically aligned fashion created by the practical critique. Rather than simply reform tests, this calls for their abolition, or on the flipside asks that tests confirm different traits, ones that could overtly realign the legitimacy of social order with pure strength or seek to create a mirror between social life and demographic life.

\section{References}

Anderson, Perry. (1993). “The Intransigent Right.” London Review of Books 14: 7-11.

Beherent, Mark. (2010). “Accidents Happen: Francois Ewald, the 'Antirevolutionary' Foucault and the Intellectual Politics of the French Welfare State." Journal of Modern History 82: 585624.

Boltanski, Luc. (2011). On Critique: A Sociology of Emancipation. London: Polity.

Boltanski, Luc and Eve Chiapell. (2005). The New Spirit of Capitalism. London: Verso.

Bourdieu, Pierre. (1958). The Sociology of Algeria. Boston: Beacon.

Bourdieu, Pierre. (1977). Outline of a Theory of Practice. Cambridge: Cambridge UP.

Bourdieu, Pierre. (1990). Logic of Practice. Stanford: Stanford: UP.

Bourdieu, Pierre. (1991). The Political Ontology of Martin Heidegger. Stanford: Stanford UP.

Bourdieu, Pierre. (2000). Pascalian Meditations. Stanford: Stanford UP.

Bourdieu, Pierre and Jean-Claude Passeron. (1977). Reproduction in Education, Society and Culture. Beverly Hills: Sage.

Bourdieu, Pierre and Jean-Claude Passeron. (1979[1964]). The Inheritors. Chicago: University of Chicago Press.

Burke, Edmund. (1951[1790]). Reflections on the French Revolution. London: Dent and Sons.

Eagleton, Terry. (1989). “Aesthetics and Politics in Burke.” History Workshop Journal 28: 53-62. 
Foucault, Michel (1967[1961]). Madness and Civilization. New York: Mentor.

Foucault, Michel. (1977). Discipline and Punish. New York: Vintage.

Foucault, Michel. (1978). History of Sexuality, Volume 1. New York: Vintage.

Foucault, Michel. (1984). “What is Enlightenment?” Pp. 32-50 in The Foucault Reader. New York: Pantheon.

Foucault, Michel (1988). "Truth, Power and Self: An Interview." pp. 9-15 in Technologies of the Self: A Seminar with Michel Foucault. Amherst: University of Massachusetts Press.

Foucault, Michel. (1993) "About the Beginnings of the Hermeneutics of the Self: Two Lectures at Dartmouth." Political Theory 21: 198-227.

Foucault, Michel. (1997). “What is Critique?” Pp. 41-81 in The Politics of Truth. Cambridge: Semiotexte.

Foucault, Michel. (2007[1977-78]). Security, Population, Territory. New York: Palgrave.

Foucault, Michel. (2008[1978-1979]). The Birth of Biopolitics. New York: Palgrave.

Fourcade, Marion. (2016). “Ordinalization.” Sociological Theory 34: 175-195.

Hayek, Friedrich. (1948). Individualism and Economic Order. London: Routledge.

Hayek, Friedrich. (1952). The Sensory Order. Chicago: University of Chicago Press.

Hayek, Friedrich. (1966). “Principles of Liberal Social Order.” Il Politico 31: 601-618.

Hobbes, Thomas. (1982[1651]). Leviathan. London: Penguin.

Lemieux, Cyril. (2008). “Scene Change in French Sociology?” L'il Sociologique.

Marx, Karl. (1978[1843]). “On the Jewish Question.” pp. 26-46 in The Marx-Engels Reader. New York: Norton.

Mark, Karl. (1978[1844-45]). “Theses on Feuerbach.” Pp. 143-146 in The Marx-Engels Reader. New York: Norton.

Marx, Karl and Friedrich Engels (1998[1844-45]). The German Ideology. New York: Prometheus.

Mehta, Uday. (1990). “Liberal Strategies of Exclusion.” Politics \& Society 18: 427-454.

Oakeshott, Michael. (1962). Rationalism in Politics and Other Essays. London: Methuen. 
Oakeshott, Michael. (1975). On Human Conduct. Oxford: Clarendon.

Oakeshott, Michael. (2000[1946]). “Hobbes on Civil Association.” Introduction to Leviathan. Oxford: Blackwell.

Ortner, Sherry. (1984). "Theory in Anthropology Since the Sixties." Comparative Studies in Society and History 26: 126-166.

Potthast, Jorg. (2017). “The Sociology of Conventions and Testing." Pp. 337-361 in Social Theory Now. Chicago: University of Chicago Press.

Reckwitz, Andreas. (2002). "Toward a Theory of Social Practices.” European Journal of Social Theory 5: 243-263.

Robin, Corey. (2017). The Reactionary Mind: Conservatism from Edmund Burke to Donald Trump. New York: Oxford UP.

Rouse, Joseph. (2007). "Practice Theory." Pp. $499-540$ in Handbook for the Philosophy of Science, Vol. 15. Amsterdam: Elsevier.

Shapin, Steven and Simon Schaffer. (1986). Leviathan and the Air-Pump. Princeton: Princeton UP.

Streeck, Wolfgang. (2011). "How to Study Contemporary Capitalism?" European Journal of Sociology 53: 1-28.

Turner, Stephen. (1994). The Social Theory of Practices. Chicago: University of Chicago Press.

Turner, Stephen. (2003). "Tradition and Cognitive Science: Oakeshott's Undoing of the Kantian Mind." Philosophy of the Social Sciences 33: 53-76.

Turner, Stephen. (2007). “Practice Then and Now.” Human Affairs 17: 111-125.

Yack, Bernard. (1986). The Longing for Total Revolution. Princeton: Princeton UP.

Zamora, Daniel and Michael Beherent (eds). (2015). Foucault and Neoliberalism. London: Polity. 


$\begin{array}{cc}\text { Left } & \text { Right } \\ \text { Critique } & \text { Confirmation } \\ \text { Politicize } & \text { Depoliticize } \\ \text { History } & \text { Temporality } \\ \text { Situated } & \text { Preservation } \\ \text { Change } & \text { Homogeneity } \\ \text { Differentiation } & \end{array}$

Table 1: Left and Right Practice Theory 